\title{
Vitamin D status in mothers with pre-eclampsia and their infants: a case-control study from Serbia, a country without a vitamin D fortification policy
}

\author{
Marija Diekic-lvankovic ${ }^{1,2}$, Hope Weiler ${ }^{2}$, Glenville Jones ${ }^{3}$, Martin Kaufmann $^{3}$, \\ Jovana Kaludjerovic ${ }^{4}$, Vesna Aleksic-Velickovic ${ }^{1}$, Ljuba M Mandić ${ }^{5}$ and Maria Glibetic ${ }^{1, *}$ \\ ${ }^{1}$ Centre of Research Excellence in Nutrition and Metabolism, Institute for Medical Research, University of Belgrade, \\ Tadeusa Koscuska 1, 11000 Belgrade, Serbia: ${ }^{2}$ School of Dietetics and Human Nutrition, McGill University, \\ Macdonald Campus, Ste Anne-de-Bellevue, Québec, Canada: ${ }^{3}$ Department of Biomedical \& Molecular Sciences, \\ Queen's University, Kingston, Ontario, Canada: ${ }^{4}$ Harvard School of Dental Medicine, Boston, MA, USA: ${ }^{5}$ Faculty of \\ Chemistry, University of Belgrade, Belgrade, Serbia
}

Submitted 8 September 2015: Final revision received 6 February 2016: Accepted 15 February 2016: First published online 18 April 2016

\begin{abstract}
Objective: The objective of the present study was to determine if vitamin D intake and status are associated with pre-eclampsia in a country without a vitamin D fortification policy.

Design: A case-control study of pregnancies with (case) and without (control) pre-eclampsia was conducted from January to April when UVB is minimal. Maternal and cord blood obtained at delivery were measured for plasma 25-hydroxycholecalciferol (25-OH-D $)$, 3-epimer of 25-OH-D 3 (3-epi-25-OH-D 3 ) and 24,25 -dihydroxycholecalciferol $\left(24,25-(\mathrm{OH})_{2} \mathrm{D}_{3}\right)$ by LC-MS/MS and maternal 1,25-dihydroxyvitamin D (1,25-(OH) $2 \mathrm{D})$. Differences between groups were tested with ANOVA and Bonferroni post hoc tests $(P<0 \cdot 05)$.

Setting: Clinical Center of Serbia.

Subjects: Pregnant women with and without pre-eclampsia ( $n$ 60) and their infants.

Results: Exogenous vitamin D intake $(0 \cdot 95-16 \cdot 25 \mu \mathrm{g} / \mathrm{d}(38-650 \mathrm{IU} / \mathrm{d}))$ was not significantly different between groups. Women with pre-eclampsia delivered infants at an earlier gestational age and had significantly lower mean total plasma 25-hydroxyvitamin D (25-OH-D; case: $11 \cdot 2$ (sD 5.1); control: $16 \cdot 1$ (sD 5.7) ng/ml; $P=0 \cdot 0006)$, 25-OH-D 3 (case: $10 \cdot 0$ (sD 4.9); control: $14 \cdot 2$ (sD $5 \cdot 8) \mathrm{ng} / \mathrm{ml} ; P=0 \cdot 002$ ), 3-epi-25-OH-D 3 (case: $0.5(\mathrm{sD} 0 \cdot 2)$; control: $0.7(\mathrm{sD} 0 \cdot 2) \mathrm{ng} / \mathrm{ml} ; P=0.0007)$ and 1,25-(OH) $)_{2} \mathrm{D}$ (case: 56.5 (sD 26.6); control: $81 \cdot 0$ (sD 25.7) pg/ml; $P=0 \cdot 018$ ), while $24,25-(\mathrm{OH})_{2} \mathrm{D}_{3}$ was not different between groups. Infants did not differ in total plasma 25-OH-D, 25-OH-D 3 , 3-epi-25-OH-D 3 and $24,25-(\mathrm{OH})_{2} \mathrm{D}_{3}$, but the mean proportion of 3 -epi-25-OH-D 3 was higher in the infant case group (case: 7.9 (sD 1.1); control: $7 \cdot 0$ (sD 1.4) \% of total $25-\mathrm{OH}-\mathrm{D}_{3} ; P=0.005$ ).

Conclusions: A high prevalence of vitamin D deficiency, as defined by plasma $25-\mathrm{OH}-\mathrm{D}<12 \mathrm{ng} / \mathrm{ml}$, was observed in $47 \%$ of all mothers and $77 \%$ of all infants. These data underscore the need for prenatal vitamin D supplementation and a food fortification policy in Serbia.
\end{abstract}

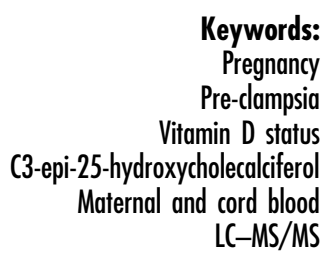

Pre-eclampsia (PE) is a maternal complication in pregnancy characterized by hypertension. It accounts for $2-8 \%$ of all complications during pregnancy and $16 \%$ of all maternal deaths $^{(1)}$. In a study conducted by the WHO in twenty-four low- and middle-income countries, the prevalence of $\mathrm{PE}$ and eclampsia combined was $4 \%^{(2)}$. $\mathrm{PE}$, as a placentadependent disorder, can lead to intra-uterine growth restriction and premature delivery, which pose a health threat to the developing child ${ }^{(2)}$. The aetiology of PE remains unknown and poorly characterized with regard to the pathophysiology involved in the development of hypertension. Nevertheless, the pathogenesis of $\mathrm{PE}$ is thought to involve a number of biological processes that may be affected by vitamin D status and availability of the 
precursor, 25-hydroxycholecalciferol $\left(25-\mathrm{OH}-\mathrm{D}_{3}\right)$, that is subsequently activated to the hormone 1,25dihydroxycholecalciferol $\left(1,25-(\mathrm{OH})_{2} \mathrm{D}_{3}\right)^{(3)}$.

The latest narrative review ${ }^{(4)}$ together with two systematic reviews of twenty-five studies found that inadequate vitamin D status (defined as 25-hydroxyvitamin D (25OH-D) $<20 \mathrm{ng} / \mathrm{ml}$ ) during pregnancy increased the risk of $\mathrm{PE}^{(5,6)}$. More importantly, a meta-analysis of data from twenty-four studies found that women with circulating $25-\mathrm{OH}-\mathrm{D}_{3}$ levels less than $20 \mathrm{ng} / \mathrm{ml}(50 \mathrm{nmol} / \mathrm{l})$ in pregnancy experienced an increased risk of $\mathrm{PE}$, preterm birth and small-for-gestational-age infants ${ }^{(7,8)}$, which is in agreement with previous publications ${ }^{(9-11)}$. However, almost all the studies included in the meta-analysis were from countries that enrich foods with vitamin $\mathrm{D}$, raising the question of whether the pattern is the same in countries without a vitamin D food fortification policy. A recently published case-cohort study of women at 26 weeks' gestation or less, carried out before the fortification programme in the USA (1959-1966), revealed that pregnant women with 25-OH-D levels of $20 \mathrm{ng} / \mathrm{ml}$ or higher had a $40 \%$ reduction in severe PE risk compared with 25-OH-D levels less than $20 \mathrm{ng} / \mathrm{ml}^{(12)}$.

More recently, the epimer of 25-hydroxycholecalciferol (3-epi-25-OH-D $\mathrm{D}_{3}$ ) has been found to represent up to $40 \%$ of the total 25-OH-D in infants and $17 \%$ in adults ${ }^{(13-16)}$. To date, the role and function of $3-\mathrm{epi}-25-\mathrm{OH}-\mathrm{D}_{3}$ are unknown but it has been suggested to have less calcaemic activity $^{(17)}$ and could thus pose a greater risk of hypertensive disorders when total vitamin D status is low. However, there is no input by authorities regarding interpretation of 3-epi-25-OH-D $\mathrm{D}_{3}$ and the Institute of Medicine recommends that serum/plasma total 25-OH-D of only $20 \mathrm{ng} / \mathrm{ml}(50 \mathrm{nmol} / \mathrm{l})$ is needed to support bone health while values below $12 \mathrm{ng} / \mathrm{ml}(30 \mathrm{nmol} / \mathrm{l})$ are generally consistent with deficiency ${ }^{(18)}$.

To achieve optimal health, it is important that women of reproductive age, pregnant mothers and their newborn infants receive adequate amounts of vitamin $\mathrm{D}$. The RDA for vitamin $\mathrm{D}$ was advised as $15 \mu \mathrm{g} / \mathrm{d}$ (600 IU/d) for covering the requirements of $97.5 \%$ of the population for ages 1-70 years and as $10 \mu \mathrm{g} / \mathrm{d}(400 \mathrm{IU} / \mathrm{d})$ for breast-fed infants (0-12 months) ${ }^{(19)}$. Oral intakes of vitamin D are sometimes unable to meet the requirements in pregnancy even with regular use of prenatal vitamins ${ }^{(20-22)}$. In the context of Serbia where food sources are limited and single vitamin D supplements for adults are rarely present in the market, the primary source of vitamin D is UVB, which is limited during winter from October to March. The winter period is characterized by a higher incidence of PE in Serbia ${ }^{(23)}$. According to the Serbian national health-care programme, it is mandatory for infants (0-12 months) to receive vitamin D drops (10-15 $\mu \mathrm{g} / \mathrm{d}(400-600 \mathrm{IU} / \mathrm{d})$ ), but there is no similar practice for adults. Available data indicate that for Serbian adults, the intake of vitamin $\mathrm{D}$ is below the recommended dietary intake of $15 \mu \mathrm{g} / \mathrm{d}(600 \mathrm{IU} / \mathrm{d})^{(24,25)}$.
The aim of the present study was to examine vitamin D intake and status of women with and without PE and their newborn infants in Serbia, a country without a mandatory vitamin $\mathrm{D}$ food fortification policy, and to describe the proportion of total $25-\mathrm{OH}-\mathrm{D}_{3}$ in the 3 -epimeric form in relation to maternal and neonatal outcomes. The hypothesis was that at delivery, women with $\mathrm{PE}$ and their infants would have lower vitamin D status based on total 25-OH-D, 25-OH-D 3 and 3-epi-25-OH-D 3 compared with healthy control pregnancies.

\section{Materials and methods}

\section{Participants}

As a part of a national integrated project, a case-control study was conducted between January and the beginning of April 2011, when UVB exposure is minimal. After hospital admission for childbirth at the Department of Gynecology and Obstetrics, a Clinical Center of Serbia, pregnant women were invited to participate in the study. Selection bias was minimized by recruiting from the major Clinical Center managing PE in Serbia. In the study time frame all women with PE were recruited, which represents more than $75 \%$ of all PE cases treated in hospital over the year ${ }^{(23)}$. In order to match cases and controls, the next healthy woman of similar age, admitted for childbirth, was invited to participate. All women with PE and $91 \%$ ( $n$ 33) of approached controls agreed to participate. Sixty mothers and their infants completed the study. Written consent was obtained from all mothers. Half of the mothers met criteria for PE (case) and half were healthy matched controls (control). Inclusion criteria for all mothers were: nulliparity, monofetal pregnancy, non-smokers and previously healthy women. Diagnostic criteria for PE were based on WHO criteria: systolic blood pressure above $140 \mathrm{mmHg}$ and diastolic blood pressure above $90 \mathrm{mmHg}$, as well as proteinuria. Gestational age was established based on last menstrual date confirmed by sonographic examination prior to 20 weeks of gestation. Cases and controls were matched 1:1 based on maternal age (19-35 years) and time frame of recruitment (week of delivery). Immediately before or after delivery, maternal blood samples were collected and all mothers completed a validated Women and Reproductive Health FFQ (WRH-FFQ) to determine their vitamin D intake from diet and vitamin D supplements. At delivery, umbilical cord blood was collected. Maternal and infant characteristics were obtained from the medical record.

\section{FFQ}

The WRH-FFQ was developed and validated against three $24 \mathrm{~h}$ recalls in Serbia ${ }^{(25)}$. Using the WRH-FFQ, women were asked to report the portion size and frequency of food items consumed in the month prior to delivery. During the interview a trained dietitian provided women 
with instructions relating to frequencies of consumption and portion sizes (small, medium, large) presented as photographs included in the WRH-FFQ. The questionnaire contained ninety food items and twelve additional questions regarding the frequency of use of multivitamin/ mineral and supplements as well as imported vitamin D-fortified products available in Serbia. The WRH-FFQ also contained a general questionnaire on age, education level, previous medical conditions, detailed vitamin supplements and medication use, lifestyle habits (smoking, physical activity/exercise, alcohol and coffee/ tea consumption) as well as exposure to solariums or UV lamps (tanning) during the last 3 months.

\section{Calculation of nutrient intakes}

Nutrient intakes resulting from the FFQ were estimated using the Serbian food composition database ${ }^{(26)}$. Manufacturers' specifications were used to estimate the nutrient content of supplements. The total daily intake of vitamin D (IU/d) was calculated using the dietary assessment software tool DIET ASSESS $^{(27,28)}$. Total vitamin D intake was calculated by adding intakes from supplements to intakes from food. Total vitamin D intakes of mothers were expressed relative to both the Estimated Average Requirement (EAR) of $10 \mu \mathrm{g} / \mathrm{d}$ ( $400 \mathrm{IU} / \mathrm{d})$ and the RDA for vitamin D of $15 \mu \mathrm{g} / \mathrm{d}(600 \mathrm{IU} / \mathrm{d})$ for adults (19-50 years) according to the Institute of Medicine recommendations ${ }^{(18)}$. The proportions of women below the EAR and the RDA were calculated since these recommendations represent healthy levels of intake in accordance with good vitamin D status when exposure to UVB is minimal ${ }^{(29)}$. Since they contain detailed guidance for pregnancy, Canada's Food Guide Servings (http://www.hc-sc.gc.ca/ fn-an/food-guide-aliment/track-suivi/table_female-femme_ preg-ence_age19-50-eng.php) were used as a reference to compare daily food serving intakes of case and control women in the month before delivery.

\section{Vitamin D status assessment}

Venous blood samples of mothers on the day of delivery and umbilical cord blood were collected into lithium heparin tubes. Blood was immediately processed and plasma frozen at $-80^{\circ} \mathrm{C}$. Plasma samples were shipped to Canada (McGill University) on dry ice and stored at $-80^{\circ} \mathrm{C}$ until analysis. Maternal and cord blood samples from delivery were measured for plasma 25-OH-D 3 , 25-hydroxyergocalciferol (25-OH-D $)$, 3-epi-25-OH-D 3 , 24,25-dihydroxycholecalciferol $\left(24,25-(\mathrm{OH})_{2} \mathrm{D}_{3}\right)$ and total $25-\mathrm{OH}-\mathrm{D}$ by LC-MS/MS at Queen's University $^{(30)}$. LC-MS/MS analysis involved running plasma extracts in triplicate along with sets of calibrators and quality control samples. Samples from the Vitamin D External Quality Assessment Scheme (DEQAS), with National Institute of Standards and Technology (NIST) reference values, were used as quality assurance samples. Inter-assay variability between the batches of LC-MS/MS assays for $25-\mathrm{OH}-\mathrm{D}_{3}$ usually has a bias between $-0.7 \%$ and $-17 \%$ from the reference DEQAS/NIST values. DEQAS certifies laboratories based upon $75 \%$ of results lying within a $\pm 15 \%$ deviation from NIST reference values. The LC-MS/MS method fell well within these limits. Quality control curves for $25-\mathrm{OH}-\mathrm{D}_{2}$ were employed, but were disregarded as the samples showed low 25-OH-D 2 content. Although 24,25$(\mathrm{OH})_{2} \mathrm{D}_{3}$ calibrators spiked with $24 R, 25-(\mathrm{OH})_{2} \mathrm{D}_{3}$ were employed, currently there is no external quality assessment scheme for this analyte as DEQAS/NIST is yet to formally assign $24,25-(\mathrm{OH})_{2} \mathrm{D}_{3}$ content to the DEQAS circulated samples. Plasma 1,25-dihydroxyvitamin D (1,25-(OH) $\left.)_{2} \mathrm{D}\right)$ was assessed by ELISA competitive enzyme immunoassay (Alpco, Salem, NH, USA) for twenty-eight mothers (case: $n$ 14; control: $n$ 14) where sufficient volume of sample was available. The intra-assay $\mathrm{CV}$ for $1,25-(\mathrm{OH})_{2} \mathrm{D}$ was $8.6 \%$.

\section{Biochemical parameters and mineral status assessment}

Standard biochemistry was obtained from the hospital chart. Biochemical tests (see online supplementary material, Supplemental Table 1) performed as part of the routine patient care were recorded for mothers, including renal function (serum creatinine, urea), liver function (bilirubin, alanine transaminase, aspartate transaminase and $\gamma$-glutamyl transferase) and an acute-phase reactant (C-reactive protein (CRP)). Analyses were performed in the certified laboratory of the Clinical Center of Serbia, which participated in the Serbian National External Quality Assessment Scheme (SNEQAS) for medical biochemistry programmes and obtained a Certificate of Proficiency for 2011-2012. Standard biochemical parameters were analysed on a Beckman Coulter AU480 Chemistry System, complete blood count on a haematological analyser (Abbott Cell-Dyn ${ }^{\circledR}$ 3700) and CRP was analysed using laser nephelometry (Siemens BN ProSpec System). Plasma and cord levels of $\mathrm{Ca}, \mathrm{Mg}, \mathrm{Fe}, \mathrm{Zn}$ and $\mathrm{Cu}$ were determined by flame atomic absorption spectroscopy on a Varian SpectrAA-10 instrument according to a previously described method ${ }^{(31)}$. The Se level in plasma samples was measured by flow injection hydride generation atomic absorption spectrometry on the same spectrometer equipped with a Varian VGA-76 hydride unit ${ }^{(32)}$. The intra-assay CV for $\mathrm{Mg}, \mathrm{Fe}, \mathrm{Zn}, \mathrm{Cu}$ and Se were $1.24 \%, 3.42 \%, 2.25 \%$, $3.07 \%$ and $5.63 \%$, respectively.

\section{Ethical approval}

The study was conducted according to the guidelines set in the Declaration of Helsinki and all procedures were approved by the Ethics Review Board of the Clinical Center of Serbia and the McGill University Research Ethics Board of the Faculty of Agricultural and Environmental Sciences for analyses in Canada.

\section{Statistical analysis}

Characteristics of mothers with and without PE were compared using the $\chi^{2}$ test or Fisher's exact test for 
categorical variables and Student's unpaired $t$ test for continuous variables. To identify differences between cases and controls a mixed-model ANOVA was used followed by Bonferroni post hoc testing. Normality (Kolmogorov-Smirnov test) and homogeneity of variances (Levene's test) were tested prior to post hoc Bonferroni testing. Non-parametric correlation analyses were used to relate plasma levels of vitamin $\mathrm{D}$ with maternal and neonatal outcomes since data were not normally distributed. Linear multiple regression analyses were performed to explore linkages between CRP, as a dependent variable, and minerals and vitamin $D$ metabolites as independent variables. A $P$ value of $\leq 0.05$ was accepted as significant. Data are expressed as mean and standard deviation unless otherwise stated. All analyses were performed using the statistical software package SAS version $9 \cdot 4$.

\section{Results}

There were no differences between the case and control groups with respect to mother's age, as shown in Table 1. However, BMI pre-pregnancy and at delivery were significantly higher in mothers with PE. Case infants were delivered predominantly by caesarean section at an earlier gestational age compared with controls (Table 1), with the latter resulting in a significant difference in all anthropometric measurements between infant groups (Table 2). Moreover, the weight-for-age $Z$-score suggested that the case infants were smaller for gestational age and sex. Apgar scores were also lower in the case infants.

Estimated daily energy and nutrient intakes assessed by the WRH-FFQ and numbers of food servings are shown in Table 3. Divergence in dietary patterns of case compared with control mothers on a daily basis was reflected in higher intakes of meat and grain food servings, chocolate and amount of oil used for cooking without meeting recommendations for daily vegetable, fruit and milk servings (Table 3 ). The top five food sources of vitamin D identified by the WRH-FFQ were meat, eggs and fatty fish, with all fish varieties being imported except trout. Regardless of group, more than $75 \%$ of mothers drank $250 \mathrm{ml}$ of coffee and $250 \mathrm{ml}$ of herbal tea (peppermint or chamomile tea) every day, while $55 \%$ consumed at least $250 \mathrm{ml}$ of soft drinks daily.

Case and control mothers had almost identical mean vitamin D intakes from supplements and diet (Table 1). Overall, vitamin D intake assed by the WRH-FFQ was below the EAR $(10 \mu \mathrm{g} / \mathrm{d}(400 \mathrm{IU} / \mathrm{d}))$ for $77 \%$ of all mothers

Table 1 Characteristics of mothers in the case (with pre-eclampsia) and control group (without pre-eclampsia), Serbia, January-April 2011

\begin{tabular}{|c|c|c|c|c|c|}
\hline & \multicolumn{2}{|c|}{ Case group (n 30) } & \multicolumn{2}{|c|}{ Control group (n 30) } & \multirow[b]{2}{*}{$P$ value } \\
\hline & Mean or $n$ & SD or $\%$ & Mean or $n$ & SD or $\%$ & \\
\hline Age (years), mean and SD & $28 \cdot 6$ & 4.9 & 28.4 & 4.5 & 0.7379 \\
\hline \multicolumn{6}{|l|}{ Anthropometric parameters } \\
\hline $\begin{array}{l}\text { Pre-pregnancy BMI }\left(\mathrm{kg} / \mathrm{m}^{2}\right) \text {, mean and SD } \\
\text { Pre-pregnancy }\end{array}$ & $23 \cdot 7$ & 4.5 & $21 \cdot 4$ & $2 \cdot 6$ & 0.0258 \\
\hline Underweight, $n$ and $\%$ of total & 0 & - & 3 & $10 \cdot 0$ & \\
\hline Healthy, $n$ and $\%$ of total & 22 & $73 \cdot 3$ & 21 & $70 \cdot 0$ & 0.735 \\
\hline Overweight, $n$ and $\%$ of total & 5 & $16 \cdot 7$ & 6 & $20 \cdot 0$ & \\
\hline Obese, $n$ and $\%$ of total & 3 & $10 \cdot 0$ & 0 & - & \\
\hline Pregnancy weight gain $(\mathrm{kg})$, mean and SD & $18 \cdot 5$ & 8.7 & $15 \cdot 8$ & $7 \cdot 0$ & 0.2577 \\
\hline BMI at delivery $\left(\mathrm{kg} / \mathrm{m}^{2}\right)$, mean and SD & $30 \cdot 5$ & $6 \cdot 8$ & $27 \cdot 4$ & 3.8 & 0.0391 \\
\hline \multicolumn{6}{|l|}{ Vitamin D intake } \\
\hline Total intake $(\mu \mathrm{g} / \mathrm{d})$, mean and SD & $7 \cdot 32$ & 3.38 & $7 \cdot 84$ & 4.60 & 0.3658 \\
\hline Total intake (IU/d), mean and SD & 292.9 & $135 \cdot 2$ & 313.7 & $183 \cdot 8$ & 0.3658 \\
\hline Supplemental intake $(\mu \mathrm{g} / \mathrm{d})$, mean and SD & 3.79 & $3 \cdot 71$ & 5.00 & $3 \cdot 80$ & 0.2345 \\
\hline Supplemental intake (IU/d), mean and SD & $151 \cdot 7$ & $148 \cdot 5$ & $200 \cdot 0$ & $151 \cdot 9$ & 0.2345 \\
\hline Dietary intake $(\mu \mathrm{g} / \mathrm{d})$, mean and SD & 3.66 & $2 \cdot 14$ & 3.34 & 1.77 & 0.6351 \\
\hline Dietary intake (IU/d), mean and SD & $146 \cdot 2$ & $85 \cdot 7$ & $133 \cdot 7$ & $70 \cdot 7$ & 0.6351 \\
\hline \multicolumn{6}{|l|}{ Pregnancy-related parameters } \\
\hline $\begin{array}{l}\text { Gestational age at delivery (weeks), mean and SD } \\
\text { Delivery type }\end{array}$ & $36 \cdot 3$ & $2 \cdot 1$ & $37 \cdot 7$ & 0.5 & 0.029 \\
\hline Caesarean section, $n$ and $\%$ of total & 21 & $70 \cdot 0$ & 1 & $3 \cdot 3$ & $<0.0001$ \\
\hline Vaginal, $n$ and $\%$ of total & 9 & $30 \cdot 0$ & 29 & $96 \cdot 7$ & $<0.0001$ \\
\hline Max. SBP (mm Hg), mean and SD & 167 & 18 & 122 & 12 & $<0.0001$ \\
\hline Max. DBP (mmHg), mean and SD & 109 & 11 & 78 & 8 & $<0.0001$ \\
\hline \multicolumn{6}{|l|}{ Biochemical parameters } \\
\hline $\mathrm{Hb}(\mathrm{g} / \mathrm{l})$, mean and SD & 110 & 15 & 121 & 13 & 0.0084 \\
\hline Glucose $(\mathrm{mmol} / \mathrm{l})$, mean and SD & 4.3 & 0.8 & $4 \cdot 8$ & 0.7 & 0.0257 \\
\hline RBC $\left(\times 10^{12} / I\right)$, mean and SD & $3 \cdot 8$ & 0.5 & $4 \cdot 2$ & 0.5 & 0.0088 \\
\hline Le $\left(\times 10^{9} / I\right)$, mean and SD & 15 & 6 & 13 & 3 & 0.268 \\
\hline $\mathrm{PL}\left(\times 10^{9} / \mathrm{I}\right)$, mean and SD & 226 & 87 & 210 & 60 & 0.3703 \\
\hline CRP (mg/l), mean and SD & 43 & 38 & 7 & 7 & $<0.0001$ \\
\hline
\end{tabular}

SBP, systolic blood pressure; DBP, diastolic blood pressure; RBC, red blood cells; Le, leucocytes; PL, platelets; CRP, C-reactive protein. 
Table 2 Characteristics at birth of infants in the case (mothers with pre-eclampsia) and control group (mothers without pre-eclampsia), Serbia, January-April 2011

\begin{tabular}{|c|c|c|c|c|c|}
\hline & \multicolumn{2}{|c|}{ Case group ( $n$ 30) } & \multicolumn{2}{|c|}{ Control group ( $n$ 30) } & \multirow[b]{2}{*}{$P$ value } \\
\hline & Mean or $n$ & SD or $\%$ & Mean or $n$ & SD or $\%$ & \\
\hline Gestational age (weeks), mean and SD & $36 \cdot 29$ & $2 \cdot 12$ & $37 \cdot 71$ & 0.54 & 0.029 \\
\hline Apgar score at $1 \mathrm{~min}$, mean and SD & $7 \cdot 2$ & 1.5 & 8.9 & 0.2 & $<0.0001$ \\
\hline Apgar score at $5 \mathrm{~min}$, mean and $\mathrm{SD}$ & 7.9 & 1.3 & $9 \cdot 0$ & 0.0 & $<0.0001$ \\
\hline Boys, $n$ and $\%$ of total & 13 & $43 \cdot 3$ & 18 & $60 \cdot 0$ & \\
\hline \multicolumn{6}{|l|}{ Anthropometric measurements } \\
\hline Head circumference $(\mathrm{cm})$, mean and SD & $33 \cdot 3$ & $2 \cdot 2$ & 34.8 & 1.0 & 0.0007 \\
\hline Length $(\mathrm{cm})$, mean and SD & $47 \cdot 8$ & $4 \cdot \overline{1}$ & $50 \cdot 9$ & 1.7 & 0.0007 \\
\hline Weight $(\mathrm{g})$, mean and SD & 2644 & 826 & 3367 & 360 & $<0.0001$ \\
\hline Weight-for-age $Z$-score*, mean and SD & -0.50 & $1 \cdot 19$ & 0.37 & 0.67 & $<0.0001$ \\
\hline
\end{tabular}

${ }^{*}$ Adjusted for gestational age and sex ${ }^{(58,59)}$.

Table 3 Dietary intake of case (with pre-eclampsia) and control (without pre-eclampsia) women in the month before delivery, Serbia, January-April 2011

\begin{tabular}{|c|c|c|c|c|c|c|}
\hline \multirow[b]{3}{*}{ Macronutrients } & \multirow{3}{*}{$\frac{\text { Recommendations }}{\text { EAR } \dagger}$} & \multicolumn{4}{|c|}{ Dietary intake per day ${ }^{*}$} & \multirow[b]{3}{*}{$P$ value } \\
\hline & & \multicolumn{2}{|c|}{ Case $(n 30)$} & \multicolumn{2}{|c|}{ Control $(n 30)$} & \\
\hline & & Mean & SD & Mean & SD & \\
\hline Energy $(\mathrm{kJ})$ & 8000 & 8719 & 1690 & 7837 & 1703 & 0.0901 \\
\hline Protein $(g)$ & 71 & 92 & 24 & 77 & 22 & 0.0136 \\
\hline Fat $(\mathrm{g})$ & ND & 67 & 27 & 59 & 23 & 0.3120 \\
\hline Carbohydrate (g) & 135 & 261 & 56 & 258 & 76 & 0.3718 \\
\hline Food groups $\ddagger$ & Food Guide Servings/d§ & \multicolumn{2}{|c|}{ Servings/d } & \multicolumn{2}{|c|}{ Servings/d } & \\
\hline Vegetables and fruit & $7-8$ & \multicolumn{2}{|c|}{6} & \multicolumn{2}{|c|}{9} & \\
\hline Grain products & $6-7$ & \multicolumn{2}{|c|}{$16 \cdot 5$} & \multicolumn{2}{|c|}{$15 \cdot 5$} & \\
\hline Milk and alternatives & 2 & \multicolumn{2}{|c|}{$1 \cdot 2$} & \multicolumn{2}{|c|}{1.3} & \\
\hline Meat and alternatives & 2 & \multicolumn{2}{|c|}{$4 \cdot 1$} & \multicolumn{2}{|c|}{3.5} & \\
\hline Vegetable servings & & \multicolumn{2}{|c|}{$2 \cdot 2$} & \multicolumn{2}{|c|}{$2 \cdot 8$} & \\
\hline Fruit servings & & \multicolumn{2}{|c|}{3.8} & \multicolumn{2}{|c|}{$6 \cdot 2$} & \\
\hline \multicolumn{7}{|l|}{ Other foods } \\
\hline Chocolate $(\mathrm{g} / \mathrm{d})$ & ND & \multicolumn{2}{|c|}{40} & \multicolumn{2}{|c|}{27} & \\
\hline Meat $(g / d)$ & 75 & \multicolumn{2}{|c|}{192} & \multicolumn{2}{|c|}{151} & \\
\hline Fish $(g / d)$ & 75 & \multirow{2}{*}{\multicolumn{2}{|c|}{$\begin{array}{r}44 \\
194\end{array}$}} & \multicolumn{2}{|c|}{45} & \\
\hline Oils and fats $(\mathrm{ml} / \mathrm{d})$ & $30-45$ & & 194 & \multicolumn{2}{|c|}{182} & \\
\hline
\end{tabular}

EAR, Estimated Average Requirements; ND, not defined.

*Based on $30 \mathrm{~d}$ estimated using the Women and Reproductive Health FFQ (WRH-FFQ) ${ }^{(25)}$

†Estimated Average Requirements ${ }^{(60)}$.

IIn pregnancy include an extra two to three Food Guide Servings from any of the four food groups each day.

§Canada's food guide (http://www.hc-sc.gc.ca/fn-an/food-guide-aliment/track-suivi/table_female-femme_preg-ence_age19-50-eng.php).

(case: $86.7 \%$ ( $n$ 26/30); control: $66.7 \%(n$ 20/30)). Only one woman $(3.3 \%)$ in each group reached the RDA due to vitamin D supplement use of $15 \mu \mathrm{g} / \mathrm{d}$ (600 IU/d), whereas $23 \%$ of cases and $33 \%$ of controls met the EAR. None of the sixty mothers consumed commercially available food products with added vitamin $\mathrm{D}$ and no vitamin supplement use was reported by twelve ( $40.0 \%)$ mothers in the case and eleven (36.7\%) mothers in the control group. The majority of mothers who reported using a vitamin supplement used $6 \cdot 25 \mu \mathrm{g}$ (250 IU) of vitamin D in the form of a multivitamin pill for pregnancy (MamaVit ${ }^{\circledR}$, PharmaSwiss or Centrum Materna ${ }^{\circledR}$, Wyeth).

Although vitamin D intake was comparable between groups, as well as total blood $\mathrm{Ca}$ concentration (case: $99 \cdot 1$ (sD 8.9); control: 95.8 (sD 21.6) mg/l; $P=0.7430$ ), women with $\mathrm{PE}$ had significantly lower total plasma 25-OH-D, 25-OH-D $3,25-\mathrm{OH}-\mathrm{D}_{2}$ and 3-epi-25-OH-D 3 (Fig. 1), while 24,25-(OH) ${ }_{2} \mathrm{D}_{3}$ (case: 0.8 (SD 0.6); control: 0.8 (sD 0.4) ng/ml; $P=0.2381$ ) and $25-\mathrm{OH}-\mathrm{D}_{3}: 24,25-(\mathrm{OH})_{2} \mathrm{D}_{3}$ ratio (case: $16 \cdot 8$ (sD 6.6); control: 18.7 (sD 3.7); $P=0.2944$ ) were not different. Moreover, mothers with $\mathrm{PE}$ had significantly lower concentrations of plasma 1,25-(OH) $2 \mathrm{D}$ (case: $56 \cdot 5$ (sD 26.6); control: 81.0 (sD 25.7) $\mathrm{pg} / \mathrm{ml} ; P=0.0178$ ). Infants, on the contrary, did not differ significantly with respect to total plasma 25-OH-D, 25-OH-D 3 , 25-OH-D 2 , 3-epi-25-OH-D (Fig. 2), 24, 25-(OH) ${ }_{2} \mathrm{D}_{3}$ (case: 0.5 (sD 0.3); control: 0.5 (sD 0.2) $\mathrm{ng} / \mathrm{ml} ; P=0 \cdot 8295)$ or $25-\mathrm{OH}-\mathrm{D}_{3}: 24,25-(\mathrm{OH})_{2} \mathrm{D}_{3}$ ratio (case: 16.8 (SD 4.5); control: 19.9 (SD 4.2); $P=0.0935$ ), but similar 

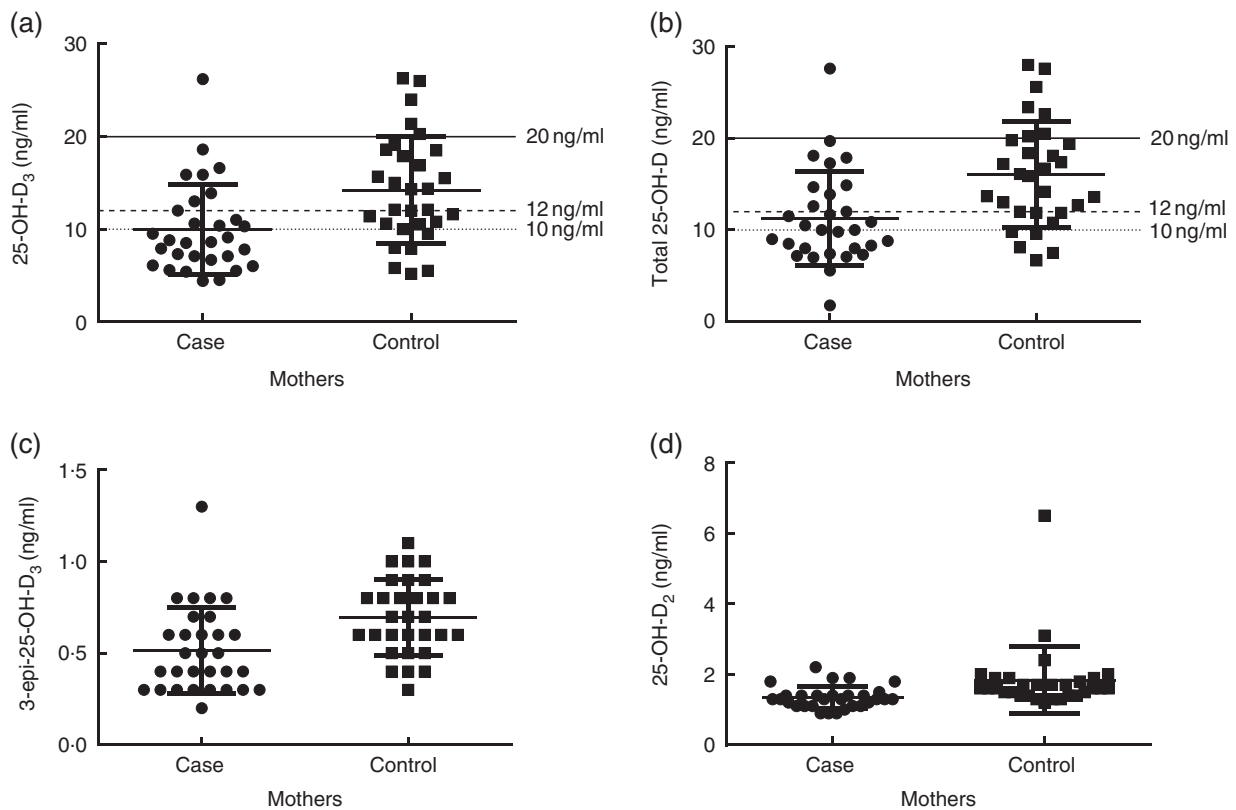

Fig. 1 Vitamin D status of mothers in the case (with pre-eclampsia; $n 30$ ) and control group (without pre-eclampsia; $n$ 30), Serbia, January-April 2011: (a) 25-hydroxycholecalciferol (25-OH- $\mathrm{D}_{3}$ ); (b) total 25-hydroxyvitamin D (25-OH-D); (c) 3-epimer of 25-hydroxycholecalciferol (3-epi-25-OH- $\mathrm{D}_{3}$ ); and (d) 25-hydroxyergocalciferol $\left(25-\mathrm{OH}-\mathrm{D}_{2}\right)$. —, $20 \mathrm{ng} / \mathrm{ml}$ target to support bone health; - - - - , below $12 \mathrm{ng} / \mathrm{ml}$ is consistent with deficiency; $\cdots .$. , below $10 \mathrm{ng} / \mathrm{ml}$ is consistent with severe deficiency. Results are presented as scatter plots with mean and SD. Differences between groups tested with the Mann-Whitney test: (a) $P=0.002$; (b) $P=0.0006$; (c) $P=0.0007$; and (d) $P<0.0001$
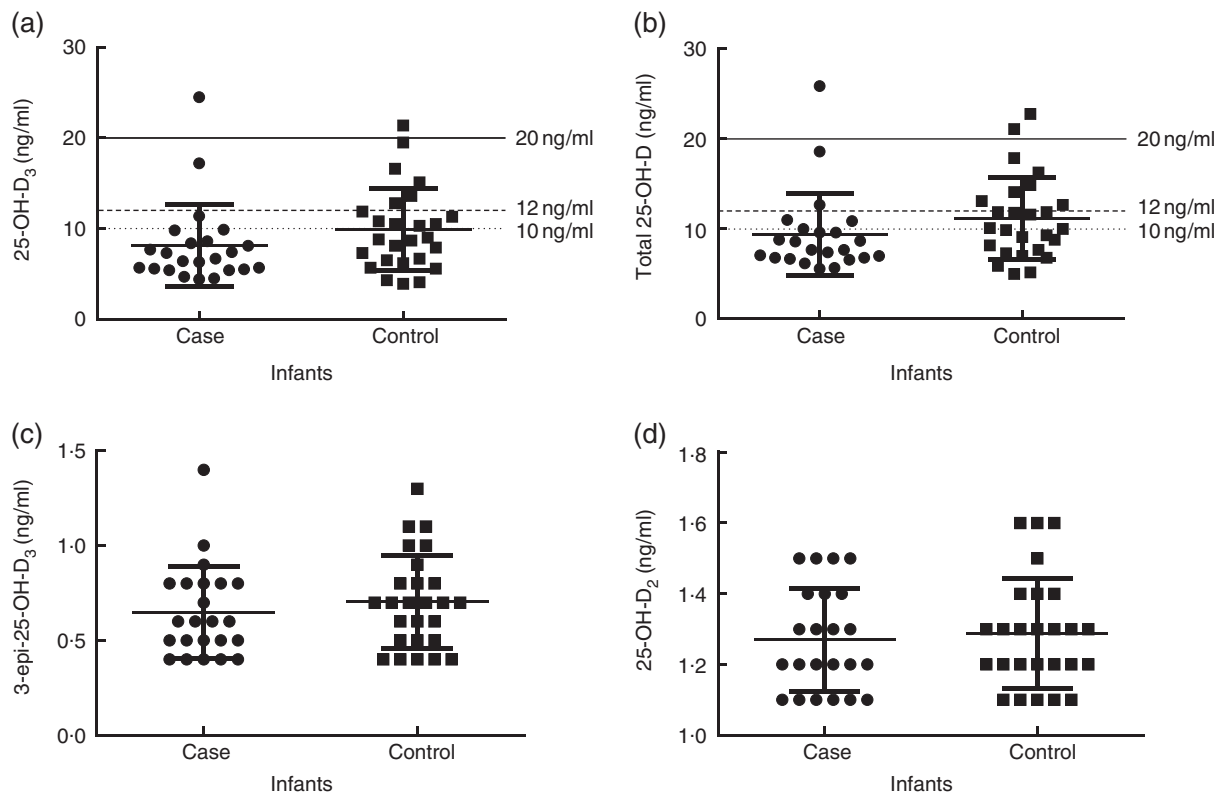

Fig. 2 Vitamin D status of infants in the case (mothers with pre-eclampsia; $n$ 23) and control group (mothers without pre-eclampsia; $n$ 26), Serbia, January-April 2011: (a) 25-hydroxycholecalciferol (25-OH- $\left.\mathrm{D}_{3}\right)$; (b) total 25-hydroxyvitamin D (25-OH-D); (c) 3-epimer of 25-hydroxycholecalciferol (3-epi-25-OH- $\left.\mathrm{D}_{3}\right)$; and (d) 25-hydroxyergocalciferol $\left(25-\mathrm{OH}-\mathrm{D}_{2}\right)$. - $20 \mathrm{ng} / \mathrm{ml}$ target to support bone health; - - - - , below $12 \mathrm{ng} / \mathrm{ml}$ is consistent with deficiency; . . . . below $10 \mathrm{ng} / \mathrm{ml}$ is consistent with severe deficiency. Results are presented as scatter plots with mean and SD. Differences between groups tested with the Mann-Whitney test: (a) $P=0.0627$; (b) $P=0.0571$; (c) $P=0.4122$; and (d) $P=0.6963$

patterns were noticed between case and control infants as in their mothers (Figs 1 and 2). Lastly, infants of mothers with PE had slightly elevated 3-epi-25-OH-D $\mathrm{D}_{3}$ content expressed as a percentage of total 25-OH-D 3 (case: 7.9 (SD 1.1); control: $7 \cdot 0$ (SD 1.4) \% of total $25-\mathrm{OH}-\mathrm{D}_{3} ; P=0.0054$ ).
In $97 \%$ of $\mathrm{PE}$ and $77 \%$ of control mothers, plasma concentration of total 25-OH-D was below $20 \mathrm{ng} / \mathrm{ml}$ (Fig. 1), a concentration needed to support bone health as identified by the Institute of Medicine. Values $<12 \mathrm{ng} / \mathrm{ml}$ were observed in $67 \%$ of case and $27 \%$ of control 
mothers, which are generally consistent with deficiency. Severe deficiency, defined as total plasma 25-OH-D level $<10 \mathrm{ng} / \mathrm{ml}^{(33)}$, was present in $47 \%$ of women with PE and $17 \%$ of controls (Fig. 1). Regardless of group, $94 \%$ of all infants had total 25-OH-D level below $20 \mathrm{ng} / \mathrm{ml}, 80 \%$ of them were deficient $(<12 \mathrm{ng} / \mathrm{ml})$ and $59 \%$ of all infants displayed severe deficiency $(<10 \mathrm{ng} / \mathrm{ml}$; Fig. 2$)$.

Mineral status is presented in Table 4. No differences were observed for maternal $\mathrm{Ca}, \mathrm{Mg}, \mathrm{Fe}, \mathrm{Zn}$ or $\mathrm{Cu}$, but $\mathrm{Se}$ was higher in the case group. In contrast, only $\mathrm{Ca}$ was lower in case infants. According to regression analyses, plasma Mg level was directly related to serum CRP in PE and $75 \%$ of the variation in CRP was associated with serum $\mathrm{Ca}, \mathrm{Mg}, \mathrm{Fe}, \mathrm{Se}, \mathrm{Cu}$ and $\mathrm{Zn}$ (adjusted $R^{2}=0.750$; see online supplementary material, Supplemental Table 2), but not with $25-\mathrm{OH}-\mathrm{D}_{3}$ and $1,25-(\mathrm{OH})_{2} \mathrm{D}$.

Weak correlations were found for maternal outcomes such as systolic and diastolic blood pressure, gestational week and BMI at delivery with 3-epi-25-OH- $\mathrm{D}_{3}$ and total 25-OH-D levels (Table 5). In infants, Spearman correlation coefficients of the 3 -epi- $25-\mathrm{OH}-\mathrm{D}_{3}$ percentage of total $25-\mathrm{OH}-\mathrm{D}_{3}$ in relation to neonatal outcomes were: $r=-0.3526(95 \%$ CI -0.5845 to $-0.06743 ; P=0.014)$ and $r=-0.3004$ (95\% CI -0.5448 to $-0.009116 ; P=0.038)$ for Apgar score at $1 \mathrm{~min}$ and $5 \mathrm{~min}$, respectively, and $r=-0.3856(95 \%$ CI -0.6091 to $-0.1053 ; P=0.007)$ for delivery type.

Regarding lifestyle, there were no reports of smoking during pregnancy; thirteen mothers reported drinking a glass of wine weekly (case: $n$ 6; control: $n$ 7); and only one control mother exercised moderately during the last month of pregnancy. Only three women reported taking a daily walk longer than $30 \mathrm{~min}$. Case and control mothers were not different with respect to percentage married (case: $100 \%$; control: $92 \%$ ), percentage living in an urban setting (case: $90 \%$; control: $93 \%$ ) or level of education, defined as high school (case: $57 \%$; control: $50 \%$ ) and post-secondary education (case: $43 \%$; control: $50 \%$ ).

\section{Discussion}

The aim of the present study was to examine vitamin D intake and status of women with and without PE and their

Table 4 Plasma minerals assessed by atomic absorption spectroscopy among the case (with pre-eclampsia) and control (without pre-eclampsia) women and infants, Serbia, January-April 2011

\begin{tabular}{|c|c|c|c|c|c|}
\hline & \multicolumn{2}{|c|}{ Case group (n 21) } & \multicolumn{2}{|c|}{ Control group ( $n$ 20) } & \multirow[b]{2}{*}{$P$ value } \\
\hline & Mean & SD & Mean & SD & \\
\hline \multicolumn{6}{|l|}{ Mothers } \\
\hline Ca (mg/l) & $99 \cdot 1$ & 8.9 & 95.7 & $22 \cdot 6$ & 0.7017 \\
\hline $\mathrm{Mg}(\mathrm{mg} / \mathrm{l})^{*}$ & $20 \cdot 5$ & 5.4 & 18.5 & 4.6 & 0.7226 \\
\hline $\mathrm{Fe}(\mathrm{mg} / \mathrm{l})$ & $2 \cdot 2$ & 1.6 & $2 \cdot 2$ & $1 \cdot 7$ & 0.8923 \\
\hline Se $(\mu g / l)$ & 63.0 & 21.4 & $46 \cdot 9$ & $12 \cdot 3$ & 0.0093 \\
\hline $\mathrm{Zn}(\mathrm{mg} / \mathrm{l})$ & 0.6 & 0.2 & 0.7 & 0.2 & 0.1021 \\
\hline $\mathrm{Cu}(\mathrm{mg} / \mathrm{l})$ & 1.9 & 0.4 & 1.7 & 0.6 & 0.5418 \\
\hline \multicolumn{6}{|l|}{ Infants } \\
\hline $\mathrm{Ca}(\mathrm{mg} / \mathrm{l})$ & $97 \cdot 6$ & $15 \cdot 9$ & $116 \cdot 6$ & $19 \cdot 4$ & 0.0012 \\
\hline $\mathrm{Mg}(\mathrm{mg} / \mathrm{l})$ & $22 \cdot 2$ & $7 \cdot 7$ & $18 \cdot 7$ & $3 \cdot 4$ & 0.1073 \\
\hline $\mathrm{Fe}(\mathrm{mg} / \mathrm{l})$ & 4.4 & 4.4 & $2 \cdot 8$ & $1 \cdot 3$ & 0.4330 \\
\hline Se $(\mu \mathrm{g} / \mathrm{l})$ & $48 \cdot 8$ & $16 \cdot 5$ & $45 \cdot 2$ & $14 \cdot 7$ & 0.4573 \\
\hline $\mathrm{Zn}(\mathrm{mg} / \mathrm{l})$ & 1.1 & 0.2 & $1 \cdot 1$ & 0.3 & 0.8672 \\
\hline $\mathrm{Cu}(\mathrm{mg} / \mathrm{l})$ & 0.4 & 0.1 & 0.4 & 0.5 & 0.0524 \\
\hline
\end{tabular}

${ }^{*}$ Case group was treated with $20 \% \mathrm{MgSO}_{4}$ for $24 \mathrm{~h}$ prior to delivery $(10 \mathrm{ml}$ intramuscularly every $8 \mathrm{~h}$ ).

Table 5 Correlations of vitamin D metabolites with maternal outcomes, Serbia, January-April 2011

\begin{tabular}{|c|c|c|c|c|}
\hline Vitamin D metabolite & Maternal outcome & Spearman correlation coefficient & $95 \% \mathrm{Cl}$ & $P$ value \\
\hline \multirow[t]{5}{*}{ 3-epi-25-OH-D 3 (ng/ml) } & BMI at delivery & -0.2178 & $-0.4590,0.0532$ & 0.1036 \\
\hline & Gestational weeks at delivery & 0.2828 & $0.0210,0.5083$ & 0.0300 \\
\hline & Max. DBP & -0.4186 & $-0.6143,-0.1745$ & 0.0010 \\
\hline & Max. SBP & -0.4704 & $-0.6529,-0.2363$ & 0.0002 \\
\hline & Delivery type & 0.3027 & $0.0427,0.5242$ & 0.0198 \\
\hline \multirow{5}{*}{ Total 25-OH-D (ng/ml) } & $\mathrm{BMI}$ at delivery & -0.2643 & $-0.4971,0.0039$ & 0.0469 \\
\hline & Gestational weeks at delivery & 0.2593 & $-0.0044,0.4892$ & 0.0474 \\
\hline & Max. DBP & -0.3857 & $-0.5892,-0.1362$ & 0.0026 \\
\hline & Max. SBP & -0.4429 & $-0.6325,-0.2032$ & 0.0004 \\
\hline & Delivery type & 0.3273 & $0.0699,0.5438$ & 0.0114 \\
\hline
\end{tabular}

3-epi-25-OH-D $\mathrm{D}_{3}$, 3-epimer of 25-hydroxycholecalciferol; 25-OH-D, 25-hydroxyvitamin D; SBP, systolic blood pressure; DBP, diastolic blood pressure. 
infants in Serbia, a country without mandatory vitamin D food fortification, and to describe the proportion of total $25-\mathrm{OH}-\mathrm{D}_{3}$ in the epimeric form in relation to maternal and neonatal outcomes.

Detailed insight into the diet of mothers showed higher intake of vitamin D-containing supplements in the control than in the case group, although overall vitamin D intake was similar. Divergent dietary patterns of case compared with control mothers were reflected in higher intakes of meat and grain food servings without meeting recommendations for daily vegetable, fruit and milk servings. Canada's food guide in pregnancy recommends including an extra two to three food servings from any of the four food groups each day (http://www.hc-sc.gc.ca/fn-an/ food-guide-aliment/track-suivi/table_female-femme_pregence_age19-50-eng.php). Mothers with PE exceeded recommended intake for twelve servings (ten grain and two meat servings) while milk, fruit and vegetable intakes did not meet targets. On the other hand, the control group exceeded recommended servings for fruit and vegetables besides grain and meat servings. A few case-control studies have suggested a beneficial effect of higher fruit and/ or vegetable (dietary fibre) consumption on $\mathrm{PE}^{(34,35)}$.

Mothers with PE had higher pre-pregnancy BMI as well as BMI at delivery. Higher consumption of protein and energy as evidenced by a greater number of daily servings of grain, meat and oils may have contributed to greater BMI at delivery. Higher BMI may have the potential to lower 25-OH-D as observed in the PE group since higher BMI and adiposity are negatively associated with vitamin D status ${ }^{(36)}$. While the total estimated intake of vitamin D may be similar between the PE and control groups, more circulating $25-\mathrm{OH}-\mathrm{D}$ may be sequestered in fat over time and be unavailable in women with greater $\mathrm{BMI}^{(36,37)}$, thus potentially contributing to lower vitamin D status in the PE group.

The most pressing observation in the current study was a high prevalence of vitamin D deficiency and insufficiency among pregnant women and their infants in Serbia. Similar results of vitamin D status were observed in women with PE from northern India (case: 9.7 (SD 4.95); control: 14.8 (SD 6.68$) \mathrm{ng} / \mathrm{ml}$ ) who did not reported using a vitamin $\mathrm{D}$ supplement ${ }^{(38)}$. In a study from Iran conducted during the winter months, mothers had higher 25-OH-D levels (case: $15 \cdot 3$ (sD 13.6); control: 23.3 (sD 15.3) ng/ml) ${ }^{(39)}$ most likely because they had more endogenous vitamin D synthesis due to the lower latitude of Iran and correspondingly higher UVB exposure compared with Serbia. In a critical review on the maternal-infant impact of vitamin D deficiency for countries with a similar latitude to Serbia, the prevalence of deficiency was between 36 and $72 \%{ }^{(22,40)}$. A recently published study on healthy mothers and infants from Turkey also reported a high incidence $(55.7 \%)$ of severe deficiency ${ }^{(41)}$. Even with vitamin D supplementation of $10 \mu \mathrm{g} / \mathrm{d}(400 \mathrm{IU} / \mathrm{d})$, the incidence of severe deficiency in women can be as high as $50 \%{ }^{(22)}$.
This is similar to results in our study where more than $50 \%$ of $\mathrm{PE}$ mothers showed severe deficiency with on average $6 \cdot 25 \mu \mathrm{g}$ (250 IU) of daily vitamin D supplementation.

In comparing mothers and infants, the cord blood $25-\mathrm{OH}-\mathrm{D}_{3}$ levels were $70 \cdot 4 \%$ of maternal values for controls and $81.1 \%$ for cases, which is in agreement with typically $75 \%$ of maternal values reported in infants ${ }^{(42)}$. A high prevalence of vitamin D deficiency (total 25-OH-D level $<12 \mathrm{ng} / \mathrm{ml}$ ) was present in mothers as well as the majority of all infants (80\%), while $74 \%$ of case and $46 \%$ of control infants displayed severe deficiency $(<10 \mathrm{ng} / \mathrm{ml})$. Similarly, a high proportion with severe deficiency (84\%) was present in PE infants from Tunis ${ }^{(43)}$. In the US cohort study conducted in the 1960s, before the vitamin D food fortification policy was implemented, a high incidence of deficiency was present in mothers and newborns ${ }^{(44)}$, pointing out that this problem exists across regions and can be mitigated by vitamin D-fortified food and supplementation. The high prevalence of vitamin D deficiency in mothers and infants in the present study highlights that this population may be at risk of developing bone diseases ${ }^{(45,46)}$ and should be supplemented with vitamin $\mathrm{D}$.

Furthermore, caution is necessary during classification into categories for vitamin D status (deficient, insufficient and adequate). LC-MS/MS detection of 3-epi-25-OH-D 3 in a relatively high percentage of total $25-\mathrm{OH}-\mathrm{D}$ raises the question of inclusion of 3-epi-25-OH- $\mathrm{D}_{3}$ in interpretation of vitamin D status, but more studies on 3-epi-25-OH-D are needed to better understand its role. This will be important for adequate treatments and so that a consensus on the appropriate cut-offs for circulating vitamin D metabolites can be established and further confirmed based on functional outcomes. Although the majority of infants were vitamin $\mathrm{D}$ deficient, 3-epi-25-OH- $\mathrm{D}_{3}$ was present and detectable in all samples. On average, the contribution of 3 -epi-25-OH-D $\mathrm{D}_{3}$ to the total $25-\mathrm{OH}-\mathrm{D}_{3}$ pool in cord blood was $7 \cdot 1 \%$ in the control and $8.1 \%$ in the case group compared with $10 \%$ for vitamin D-supplemented Canadian healthy infants ${ }^{(47)}$. Higher 3-epi-25-OH-D 3 percentages ( $43 \%$ ) were reported for Spanish infants younger than 1 month and born in winter or autumn ${ }^{(48)}$. However, $25-\mathrm{OH}-\mathrm{D}_{3}$ concentrations of Spanish $(30 \cdot 4 \mathrm{ng} / \mathrm{ml})$ and Canadian $(26 \cdot 1 \mathrm{ng} / \mathrm{ml})$ infants were higher than those of infants in our study (control: 9.88; case: $8.11 \mathrm{ng} / \mathrm{ml}$ ) suggesting that the proportion of 3-epimer might be associated with the $25-\mathrm{OH}-\mathrm{D}_{3}$ concentration and/or vitamin D supplementation. Since infants did not have significantly different 3-epi-25-OH-D $\mathrm{D}_{3}$ levels, the slight differences between groups in infant 3 -epi-25-OH-D $\mathrm{D}_{3}$ percentage content might be due to the younger mean gestational age of case infants because an inverse relationship between age and percentage of 3-epi-25-OH-D 3 in total 25-OH-D has been observed $^{(47,49)}$. 
Although the biological origin and function of 3-epi-25$\mathrm{OH}-\mathrm{D}_{3}$ in infants are unknown, a very few studies have shown that there is an increase of 3-epi-25-OH-D 3 with vitamin $\mathrm{D}$ supplementation and a dose-response pattern in infants in the first year of life ${ }^{(14,47)}$. In adult rodents it has been reported that endogenous synthesis of 3-epi-25-OH$\mathrm{D}_{3}$ follows a dose-response relationship to cholecalciferol intake without impact on bone health outcomes and with more prominent response in females compared with males ${ }^{(50)}$. Overall, more studies in animal and human subjects are needed to understand better the significance, role and function of $3-\mathrm{epi}-25-\mathrm{OH}-\mathrm{D}_{3}$ in infancy and pregnancy.

In pregnant women with diabetes mellitus type 1 , when the risk for $\mathrm{PE}$ is increased ${ }^{(51)}$, it has been reported that 3-epi-25-OH-D $\mathrm{D}_{3}$ is associated with a key marker of glycaemic control $(\mathrm{HbA} 1 \mathrm{c})^{(52)}$. There is no information available concerning the association of 3-epi-25-OH-D with PE, but the relationship between PE and vitamin D status has been studied. Bodnar and colleagues reported that maternal vitamin D deficiency may be a risk factor for severe PE, but not for its mild subtypes. Cases of PE were considered severe if they had at least one of the following: systolic blood pressure $\geq 160 \mathrm{mmHg}$, diastolic blood pressure $\geq 110 \mathrm{mmHg}$, proteinuria of $5 \mathrm{~g} / 24 \mathrm{~h}$, pulmonary oedema or convulsions/eclampsia ${ }^{(12)}$. Based on these criteria, $97 \%$ of our case group had severe PE with systolic blood pressure $\geq 160 \mathrm{mmHg}$ and diastolic blood pressure $\geq 110 \mathrm{mmHg}$, together with plasma concentration of total 25-OH-D below $20 \mathrm{ng} / \mathrm{ml}$. It is believed that at this threshold, $1,25-(\mathrm{OH})_{2} \mathrm{D}$ production is compromised. Indeed, for $43 \%$ (12/28) of all tested mothers and for $76 \%$ (13/17) of tested deficient mothers, plasma concentration of $1,25-(\mathrm{OH})_{2} \mathrm{D}$ was below $60 \mathrm{pg} / \mathrm{ml}(156 \mathrm{pmol} / \mathrm{l})$, which is recommended as a minimum level in pregnancy for the third trimester. However, 1,25- $(\mathrm{OH})_{2} \mathrm{D}$ was in the recommended reference range of $60-119 \mathrm{pg} / \mathrm{ml}$ (156-309 pmol/1) ${ }^{(53)}$ for the third trimester of pregnancy for all $(11 / 11)$ tested mothers with plasma concentration of total 25-OH-D above $12 \mathrm{ng} / \mathrm{ml}$, suggesting adequate production of $1,25-(\mathrm{OH})_{2} \mathrm{D}$.

Based on this observation compromised production of 1,25- $(\mathrm{OH})_{2} \mathrm{D}_{3}$ might be expected for $78 \%$ of all deficient infants in our study (case: $87 \%$; control: $59 \%$ ), but sufficient volume of infants' samples was not available to confirm this postulation. In addition, it has been reported previously that severe $\mathrm{PE}$ is associated with the highest risks of adverse perinatal outcomes, including preterm birth and fetal growth restriction ${ }^{(10,54-56)}$ while gestational vitamin D deficiency has been linked to increased risk of caesarean delivery and bacterial vaginosis infections ${ }^{(4,9,57)}$. In our study $52 \%$ of PE and $8 \%$ of control infants were born preterm, before 37 weeks of pregnancy, and $20 \%$ were SGA, while $70 \%$ of $\mathrm{PE}$ and $3.3 \%$ of control infants were delivered by caesarean section. Moreover, blood $\mathrm{Ca}$ was lower in case infants and they had lower overall $Z$-scores as well. Thus interventions to improve both maternal and fetal outcomes are warranted and data in our study underscore the need for prenatal educational interventions to decrease the health risks attributable to unhealthy lifestyle behaviours and eating patterns in pregnancy.

The present study displays several limitations including the lack of control of supplement compliance, the crosssectional approach, the limited number of samples and possible selection bias as the study was conducted in one Clinical Center focused on treating the most severe cases. The strength of our study is the collection of information on detailed dietary vitamin $\mathrm{D}$ intake in winter in determining the difference in vitamin D status between cases of $\mathrm{PE}$ and healthy controls.

\section{Conclusion}

The present study showed a high prevalence of vitamin $\mathrm{D}$ deficiency (total $25-\mathrm{OH}-\mathrm{D}<12 \mathrm{ng} / \mathrm{ml}$ ) observed in $47 \%$ of all mothers and $77 \%$ of all infants while almost all other participants had insufficient vitamin D status (25-OH$\mathrm{D}_{3}<20 \mathrm{ng} / \mathrm{ml}$ ). The reasons may be lack of vitamin $\mathrm{D}$ food fortification and inadequate intake of prenatal vitamins containing vitamin $\mathrm{D}$, as well as negligible subcutaneous production in the winter due to minimal UVB at $44.8^{\circ} \mathrm{N}$ latitude. Despite similar vitamin D intake from supplements and diet of PE and control mothers, women with PE had significantly lower plasma $25-\mathrm{OH}-\mathrm{D}_{3}, 3-\mathrm{epi}-25-\mathrm{OH}-\mathrm{D}_{3}$ and $1,25-(\mathrm{OH})_{2} \mathrm{D}$ while $24,25-(\mathrm{OH})_{2} \mathrm{D}_{3}$ was similar. Infants, on the contrary, did not differ significantly in total plasma $25-\mathrm{OH}-\mathrm{D}_{3}$, although case infants were born at an earlier gestational age and there was a significant difference in all anthropometric measurements between case and control infants. These data underscore that the strategy of Serbian public health should include improvement of mothers' dietary intake and sun exposure, and vitamin supplementation when needed, as well as a tight control of PE.

\section{Acknowledgements}

Acknowledgements: The authors are grateful to Sherry Agellon from McGill University who helped with vitamin D analyses and Zoran Pavlovic who helped with mineral status assessment, as well as to Marina Nikolic and Aleksandra Konic-Ristic for their advice and assistance in preparation and transport of the samples to Canada. The authors acknowledge the assistance of medical and nursing staff of the Department of Gynecology and Obstetrics, a Clinical Center of Serbia, for their help in recruiting patients and ensuring the smooth conduct of the trial. Financial support: This work was supported by the Ministry of Education, Science and Technological Development of the Republic of Serbia (grant number III 41030). The Ministry of Education, Science and Technological Development of the Republic of Serbia had 
no role in the design, analysis or writing of this article. Vitamin D analyses were funded by an unrestricted fund at McGill University. Conflict of interest: None. Authorship: M.G. and L.M.M. designed the research framework; M.D.-I., V.A.-K. and J.K. conducted the study at the Clinical Center of Serbia; H.W. and M.D.-I. formulated the research question on vitamin $\mathrm{D}$ and as lead researchers planned and conducted research on vitamin D; G.J., M.K., H.W. and M.D.-I. conducted biochemical analyses; M.D.-I. and H.W. analysed data; M.D.-I. and H.W. drafted and revised the paper; M.D.-I. had primary responsibility for final content. All authors read and approved the final manuscript. Ethics of buman subject participation: This study was conducted according to the guidelines set in the Declaration of Helsinki and all procedures were approved by Ethics Review Board in Serbia and the McGill University Research Ethics Board of the Faculty of Agricultural and Environmental Sciences for analyses in Canada. Written informed consent was obtained from all participants.

\section{Supplementary material}

To view supplementary material for this article, please visit http://dx.doi.org/10.1017/S1368980016000409

\section{References}

1. Steegers EA, von Dadelszen P, Duvekot JJ et al. (2010) Pre-eclampsia. Lancet 376, 631-644.

2. Bilano VL, Ota E, Ganchimeg T et al. (2014) Risk factors of pre-eclampsia/eclampsia and its adverse outcomes in low- and middle-income countries: a WHO secondary analysis. PLoS One 9, e91198.

3. Haugen M, Brantsaeter AL, Trogstad L et al. (2009) Vitamin D supplementation and reduced risk of preeclampsia in nulliparous women. Epidemiology 20, 720-726.

4. Genuis SJ (2015) Maternal and pediatric health outcomes in relation to gestational vitamin D sufficiency. Obstet Gynecol Int 2015, 501829.

5. Tabesh M, Salehi-Abargouei A, Tabesh M et al. (2013) Maternal vitamin D status and risk of pre-eclampsia: a systematic review and meta-analysis. J Clin Endocrinol Metab 98, 3165-3173.

6. Hypponen E, Cavadino A, Williams D et al. (2013) Vitamin D and pre-eclampsia: original data, systematic review and meta-analysis. Ann Nutr Metab 63, 331-340.

7. Wei SQ (2014) Vitamin D and pregnancy outcomes. Curr Opin Obstet Gynecol 26, 438-447.

8. Wei SQ, Qi HP, Luo ZC et al. (2013) Maternal vitamin D status and adverse pregnancy outcomes: a systematic review and meta-analysis. J Matern Neonatal Med 26, 889-899.

9. Aghajafari F, Nagulesapillai T, Ronksley PE et al. (2013) Association between maternal serum 25-hydroxyvitamin D level and pregnancy and neonatal outcomes: systematic review and meta-analysis of observational studies. BMJ 346, f1169.

10. Martineau AR \& Khan K (2014) Maternal vitamin D insufficiency is associated with adverse pregnancy and neonatal outcomes. Evid Based Med 19, e4.

11. Thorne-Lyman A \& Fawzi WW (2012) Vitamin D during pregnancy and maternal, neonatal and infant health outcomes: a systematic review and meta-analysis. Paediatr Perinat Epidemiol 26, Suppl. 1, 75-90.

12. Bodnar LM, Simhan HN, Catov JM et al. (2014) Maternal vitamin $D$ status and the risk of mild and severe preeclampsia. Epidemiology 25, 207-214.

13. Singh RJ, Taylor RL, Reddy GS et al. (2006) C-3 epimers can account for a significant proportion of total circulating 25-hydroxyvitamin $\mathrm{D}$ in infants, complicating accurate measurement and interpretation of vitamin D status. J Clin Endocrinol Metab 91, 3055-3061.

14. Gallo S, Comeau K, Vanstone C et al. (2013) Effect of different dosages of oral vitamin D supplementation on vitamin D status in healthy, breastfed infants: a randomized trial. JAMA 309, 1785-1792.

15. Gallo S, Comeau K, Agellon S et al. (2014) Methodological issues in assessing plasma 25-hydroxyvitamin D concentration in newborn infants. Bone 61, 186-190.

16. Stepman HC, Vanderroost A, Stockl D et al. (2011) Full-scan mass spectral evidence for 3-epi-25-hydroxyvitamin $\mathrm{D}(3)$ in serum of infants and adults. Clin Chem Lab Med 49 , 253-256.

17. Fleet JC, Bradley J, Reddy GS et al. (1996) $1 \alpha, 25-(\mathrm{OH})_{2^{-}}$ vitamin $\mathrm{D}_{3}$ analogs with minimal in vivo calcemic activity can stimulate significant transepithelial calcium transport and mRNA expression in vitro. Arch Biochem Biophys 329, 228-234.

18. Ross AC (2011) The 2011 report on dietary reference intakes for calcium and vitamin D. Public Health Nutr 14, 938-939.

19. Ross AC, Manson JE, Abrams SA et al. (2011) The 2011 report on dietary reference intakes for calcium and vitamin $\mathrm{D}$ from the Institute of Medicine: what clinicians need to know. J Clin Endocrinol Metab 96, 53-58.

20. Bodnar LM, Catov JM, Simhan HN et al. (2007) Maternal vitamin $\mathrm{D}$ deficiency increases the risk of preeclampsia. J Clin Endocrinol Metab 92, 3517-3522.

21. Bodnar LM, Simhan HN, Powers RW et al. (2007) High prevalence of vitamin D insufficiency in black and white pregnant women residing in the northern United States and their neonates. J Nutr 137, 447-452.

22. Lee JM, Smith JR, Philipp BL et al. (2007) Vitamin D deficiency in a healthy group of mothers and newborn infants. Clin Pediatr (Phila) 46, 42-44.

23. Velickovic VA (2012) Role, function and profile of polyunsaturated fatty acids in preeclampsia. PhD Thesis, University of Kragujevac.

24. Novakovic R, Cavelaars AE, Bekkering GE et al. (2013) Micronutrient intake and status in Central and Eastern Europe compared with other European countries, results from the EURRECA network. Public Health Nutr 16, 824-840.

25. Djekic-Ivankovic M, Weiler HA, Nikolic M et al. (2016) Validity of an FFQ assessing the vitamin D intake of young Serbian women living in a region without food fortification: the method of triads model. Public Health Nutr 19, 437-445.

26. Gurinovic M, Milesevic J, Kadvan A et al. (2016) Establishment and advances in the online Serbian food and recipe data base harmonized with EuroFIR standards. Food Chem 193, 30-38.

27. Gavrieli A, Naska A, Berry R et al. (2014) Dietary monitoring tools for risk assessment. http://www.efsa.europa.eu/en/ supporting/pub/607e.htm (accessed October 2014).

28. Gurinovic M, Milesevic J, Novakovic R et al. (2016) Improving nutrition surveillance and public health research in Central and Eastern Europe/Balkan Countries using the Balkan Food Platform and dietary tools. Food Chem 193, 173-180.

29. Ross A, Taylor C \& Yaktine A (editors) (2011) Dietary Reference Intakes for Calcium and Vitamin D, pp. 75-78. Washington, DC: Institute of Medicine.

30. Kaufmann M, Gallagher JC, Peacock M et al. (2014) Clinical utility of simultaneous quantitation of 25-hydroxyvitamin D 
and 24,25-dihydroxyvitamin $\mathrm{D}$ by LC-MS/MS involving derivatization with DMEQ-TAD. J Clin Endocrinol Metab 99, 2567-2574.

31. Qi J-X (1990) Determination of $\mathrm{Cu}, \mathrm{Zn}, \mathrm{Fe}, \mathrm{Ca}, \mathrm{Mg}, \mathrm{Na}$ and $K$ in Serum Flame by Atomic Absorption Spectroscopy. Palo Alto, CA: Varian Instruments at Works, pp. 1-2

32. Yu MW, Horng IS, Hsu KH et al. (1999) Plasma selenium levels and risk of hepatocellular carcinoma among men with chronic hepatitis virus infection. Am J Epidemiol 150 , 367-374.

33. Holick MF (2007) Vitamin D deficiency. $N$ Engl J Med 357, 266-281.

34. Zhang C, Williams MA, King IB et al. (2002) Vitamin C and the risk of preeclampsia - results from dietary questionnaire and plasma assay. Epidemiology 13, 409-416.

35. Qiu C, Coughlin KB, Frederick IO et al. (2008) Dietary fiber intake in early pregnancy and risk of subsequent preeclampsia. Am J Hypertens 21, 903-909.

36. Pourshahidi LK (2015) Vitamin D and obesity: current perspectives and future directions. Proc Nutr Soc 74, 115-124.

37. Gallagher JC, Yalamanchili V \& Smith LM (2013) The effect of vitamin D supplementation on serum $25(\mathrm{OH}) \mathrm{D}$ in thin and obese women. J Steroid Biochem Mol Biol 136, 195-200.

38. Singla R, Gurung P, Aggarwal N et al. (2015) Relationship between preeclampsia and vitamin $\mathrm{D}$ deficiency: a case control study. Arch Gynecol Obstet 291, 1247-1251.

39. Mohaghegh Z, Abedi P, Dilgouni T et al. (2015) The relation of preeclampsia and serum level of 25-hydroxyvitamin D in mothers and their neonates: a case control study in Iran. Horm Metab Res 47, 284-288.

40. Weinert LS \& Silveiro SP (2015) Maternal-fetal impact of vitamin D deficiency: a critical review. Matern Child Health J 19, 94-101.

41. Alp H, Tekgunduz KS \& Akkar MK (2016) Maternal and cord blood vitamin D status in high-altitude pregnancy. J Matern Neonatal Med 29, 571-575.

42. Kovacs CS (2013) Maternal vitamin D deficiency: fetal and neonatal implications. Semin Fetal Neonatal Med (Epublication ahead of print version).

43. Fares S, Sethom MM, Khouaja-Mokrani C et al. (2014) VitaminA, E, and D deficiencies in Tunisian very low birth weight neonates: prevalence and risk factors. Pediatr Neonatol 55, 196-201.

44. Eckhardt CL, Gernand AD, Roth DE et al. (2015) Maternal vitamin D status and infant anthropometry in a US multi-centre cohort study. Ann Hum Biol 42, 215-222.

45. Javaid MK, Crozier SR, Harvey NC et al. (2006) Maternal vitamin D status during pregnancy and childhood bone mass at age 9 years: a longitudinal study. Lancet 367, 36-43.

46. Cooper C, Javaid K, Westlake S et al. (2005) Developmental origins of osteoporotic fracture: the role of maternal vitamin D insufficiency. J Nutr 135, issue 11, 2728S-2734S.
47. Bailey D, Perumal N, Yazdanpanah M et al. (2014) Maternal-fetal-infant dynamics of the C3-epimer of 25-hydroxyvitamin D. Clin Biochem 47, 816-822.

48. Granado-Lorencio F, Garcia-Heras LM, Blanco-Navarro I et al. (2014) Assessment of 3-epi-25-OH- $\mathrm{D}_{3}$ in preterm and full term infant samples and its relationship to demographic, anthropometric and biochemical determinants. Clin Biochem 47, 853-856.

49. Yazdanpanah M, Bailey D, Walsh W et al. (2013) Analytical measurement of serum 25-OH-vitamin D(3), 25-OH-vitamin $\mathrm{D}(2)$ and their C3-epimers by LC-MS/MS in infant and pediatric specimens. Clin Biochem 46, 1264-1271.

50. Bianchini C, Lavery P, Agellon S et al. (2015) The generation of C-3 $\alpha$ epimer of 25-hydroxyvitamin D and its biological effects on bone mineral density in adult rodents. Calcif Tissue Int 96, 453-464.

51. Evers IM, de Valk HW \& Visser GH (2004) Risk of complications of pregnancy in women with type 1 diabetes: nationwide prospective study in the Netherlands. BMJ 328, 915.

52. Bennett SE, Casey C, McPeake J et al. (2014) 3-Epi-25 hydroxyvitamin $\mathrm{D}$ in pregnancy. Pregnancy Hypertens 4, 236.

53. Abbassi-Ghanavati M, Greer LG \& Cunningham FG (2009) Pregnancy and laboratory studies: a reference table for clinicians. Obstet Gynecol 114, 1326-1331.

54. Haugen G \& Helland I (2001) Influence of preeclampsia or maternal intake of omega- 3 fatty acids on the vasoactive effect of prostaglandin F-2- $\alpha$ in human umbilical arteries. Gynecol Obstet Invest 52, 75-81.

55. Zhang J, Klebanoff MA \& Roberts JM (2001) Prediction of adverse outcomes by common definitions of hypertension in pregnancy. Obstet Gynecol 97, 261-267.

56. Khalessi N, Kalani M, Araghi M et al. (2015) The relationship between maternal vitamin D deficiency and low birth weight neonates. J Family Reprod Health 9, $113-117$.

57. Olmos-Ortiz A, Avila E, Durand-Carbajal M et al. (2015) Regulation of calcitriol biosynthesis and activity: focus on gestational vitamin D deficiency and adverse pregnancy outcomes. Nutrients 7, 443-480.

58. Kramer MS, Platt RW, Wen SW et al. (2001) A new and improved population-based Canadian reference for birth weight for gestational age. Pediatrics 108, E35.

59. World Health Organization (2006) Multicentre Growth Reference Study Group. WHO Child Growth Standards: Length/ Height-for-Age, Weight-for-Age, Weight-for-Length, Weight-forHeight and Body Mass Index-for-Age: Methods and Development. Geneva: WHO; avalable at http://apps.who.int/iris/ bitstream/10665/43413/1/924154693X_eng.pdf

60. Institute of Medicine (2003) Dietary Reference Intakes: Applications in Dietary Planning. Washington, DC: National Academies Press. 